\title{
Técnica y arte del retrato y del autorretrato en Bernat Metge
}

\author{
Julia BuTiñá
}

(UNED)

Las novedades que acarreaba el Humanismo son extremadamente llamativas en torno a hechos como el de la traducción, aspecto precisamente tan estudiado en nuestros días; vamos a observar aquí la manifestación del cambio humanista, ${ }^{1}$ a través de algo concreto. Tomaremos como punto de observación los retratos, lo cual incluye el tratamiento de unos rasgos técnicos pero sin cifrarse sólo en algo formal, y nos centraremos en la obra principal de Bernat Metge - Lo somni (1399) - el gran humanista de las letras catalanas y además el primero en quien se advierte aquella nueva sensibilidad en la Península.

Como es sabido, las literarias son empresas todavía a finales del siglo XIV muy aisladas, sobre todo en el caso de Metge, caso de todos modos bastante excepcional, tanto por la percepción del hecho literario como por el dominio del mismo. Buena muestra del proceso de cambio que afectaba a aquel momento se puede apreciar en el vuelco que da este autor por medio de los géneros literarios, pasando del debate (Libre de Fortuna e Prudència) al diálogo; pero en ambas ocasiones, la audiencia que podía entenderle en profundidad debía ser mínima.

Al tratar del humanista Bernat Metge no habría que dejar de mencionar a un precedente considerado siempre como una cúspide medieval, que había preparado el cauce lingüístico - más allá de la dignificación del romance bajo el modelo del latín efectuada en la Cancillería de Barcelona-, así como también el cultural. Me refiero a Ramón Llull, gracias a quien se podía contar con una lengua que ofrecía una base madura y estructurada, a la vez que, en cuanto al pensamiento, se gozaba ya de un bagaje propio y profundo, de sello luliano. En los dos ámbitos el humanista barcelonés tiene una fuerte deuda para con el filósofo mallorquín, al margen de la afinidad filosófico-moral. ${ }^{2}$ Sin embargo, los aspec-

1 Cambio, de todos modos, que no alcanzó a las capas sociales, sino que afectó a una minoría sensibilizada hacia las Humanidades. Para aquella extensión fue necesaria «la paulatina introducción de esos mismos studia humanitatis en el ámbito de la universidad", A. Coroleu, El Humanismo en España, en Kraye 1998, p. 298; entonces será ya el momento del humanismo —renacentista- hispánico.

${ }^{2}$ La he perseguido en diferentes trabajos, reunidos algunos en Detrás de los origenes del Humanismo: Ramón Llull, UNED, Madrid 2006, 67-78, 106-143. 
tos literarios en los que nos vamos a fijar no los bebía Metge en Llull, a pesar de deberle tanto; al igual que tampoco bebía los aspectos formales del sueño de $L o$ somni en Boecio, a pesar de conocerlo y de haberlo burlado en su obra anterior, el Libre de Fortuna e Prudencia.

Ello no quiere decir que haya que desechar el interesante análisis de los retratos que aparecen en las dos llamadas novelas lulianas, Fèlix y Blanquerna, así como el de su propia figura (Ramon lo foll) y el del personaje que hace de clérigo oponente en sus debates. Pero, como hemos apuntado con Lo somni y el reflejo boeciano, en Metge no hay que tratar de buscar una continuidad hacia los autores del caudal tradicional, pues bebe de ellos sólo lo justo que puede aprovechar o bien para burlarlos, ${ }^{3}$ y, respecto a Llull, dejamos la vía para posteriores observaciones de mayor especialización.

Centrándonos en el humanista, partimos del momento en que, siendo funcionario real de la confianza del futuro Juan I, escribe el Libre de Fortuna e Prudència ${ }^{4}$ en 1381. Se trata de un poema alegórico donde el sueño aparece con los papeles usuales hasta entonces: el tradicional - en que el autor debate con aquellos personajes-y, también, el de experiencia irreal - en el marco de la obra, el autor se traslada a un trasmundo, que presenta interferencias con el mundo real- Este filete envoltorio comienza con la inquietud nocturna del autor, próxima a la muerte, que le lleva a pasear a la orilla del mar - episodio sustentado por fuentes literarias que dan las claves de lectura-, y acaba con su regreso, en un estado próximo a la ataraxia de los clásicos. Metge arremete contra el viejo género y la doctrina adyacente, pero sigue haciendo una obra que es una alegoría onírica, como bien suscriben los mismos personajes.

El debate del autor con estas figuras reproduce hasta tal punto el esquema medievalizante que hasta que no se ha dado una nueva lectura - especialmente bajo la influencia de Lucano- no se ha llegado a entender como un ataque frontal a aquella argumentación filosófica, por lo que se leía como una obra estereotipada y aburrida. Si esto ha sido así en nuestros días, la obra debía ofrecer dos lecturas también en su tiempo, como se advierte más claramente aún con el siguiente sueño de Metge.

En aquella obra, de apariencia y técnicas medievalizantes, hallamos el retrato bastante original de las dos figuras alegóricas, Fortuna y Prudencia. La primera, «vella pudent, embriaga» (ed. Olivar, 78, v. 17), deja un muy rico retrato burlesco, que contrasta con las Fortunas bellas y esplendentes que se dan habitual pero no exclusivamente en la literatura medieval"; aquí es «la pus

${ }^{3}$ En el mapa de las fuentes del libro IV de Lo somni (Butiñá 2002a, 503; remito a este estudio para mis comentarios sobre Metge, o bien de modo resumido a 2004), que trata de la virtud, el vacío de la tradición cristiana es vistoso frente a la abundancia de autores clásicos; y en el I, san Gregorio aparece para ser burlado, santo Tomás en posición ambivalente, y en buen lugar quedan sólo san Agustín y su seguidor doctrinal, Casiodoro. Sus funciones están muy claras; y si no los precisa, los olvida.

${ }^{4}$ La edición de esta obra está en prensa en la Real Academia de Buenas Letras de Barcelona, a cargo de Miquel Marco; su estudio y edición constituyeron su tesis doctoral (UNED 2004).

' Llamé la atención sobre este hecho, estudiando la figura de esta diosa y contrastándola con su representación por parte de Mena y Santillana, en El paso de "Fortuna" por la Península durante 
fera / domna que mai auzíssets dir» (ib., 68, vv. 21-22), tiene los cabellos desordenados y anda cojeando, con grotescos y tétricos bandazos (ib., vv. 27-28, y 70, vv. 4-8). La ridiculización de la Sabiduría (o Prudencia) es preferentemente moral, si bien su descripción tampoco tiene desperdicio debido al carácter irónico que, como ocurría con la anterior figura, la distingue del contexto puramente medievalizante. Por otro lado, en el marco introductorio, aunque muy esquematizados se dan rasgos esenciales de un viejo, que representa al pobre Amiclates de la Farsalia, personaje que servía en los sermones para ilustrar el ejemplo de la pobreza; con un par de objetos caracterizadores, su figura quedará estrictamente definida, pudiendo reconocerse a través de su cita en el Convivio. $^{6}$

También tendría lugar el considerar la misma figura de Metge en el debate: angustiado en el inicio, víctima inocente en el salto al trasmundo y, al final de la obra, bajo el estado de ánimo clasicista ya apuntado. Facetas que no desdicen de las que ofrece en Lo somni, pero que nos limitamos a dejar reseñadas, dado que en el debate se perciben de modo rudimentario y en sucesión cronológica según el desarrollo del relato, lo cual contrasta con la minucia y complejidad que ofrece su figura en el diálogo.

La gran obra de Metge, Lo somni, escrita a raíz de los hechos sociopolíticos que inculparon a la camarilla del rey Juan I, a su muerte (1396), constituye un diálogo sobre la inmortalidad y la virtud, en el que, emulando a los clásicos, consigue una altura formal de acuerdo con esos nobles contenidos. Esta obra es un exponente muy principal del Humanismo, quizá la que exprese mejor aquellas ideas revolucionarias, así como la que más bellamente las asume y defiende, pasándolas así a la posteridad.

la baja Edad Media, «Medievalismo. Boletín de la Sociedad Española de Estudios Medievales», III (1993), 209-232. Se da algo parecido en el Curial e Güelfa —aunque con otras implicaciones literarias, pues este autor está más pendiente del Genealogiae deorum y de Boccaccio que de las implicaciones filosóficas metgianas--, donde la Fortuna, eminentemente vitalista y burlesca, se representa asimismo sin pompa ni majestad; puede consultarse Tras los orígenes del Humanismo: El "Curial e Güelfa", UNED, Madrid 2001", 183-196, y también en visión comparatista con las letras castellanas en 273-297.

- Dibuja en las manos del viejo indigente los símbolos de un convite, un vaso y el pan, esto es el alimento espiritual que ofrecía Dante en el Convivio (I i, 12): «en l'una ma tenc un anap e en l'altra un cantell de pa" (Llibre de Fortuna e Prudencia, vv. 52-53, en Obres menors, ed. M. Olivar, Barcino, Barcelona 1927, 59). También pueden consultarse mis trabajos — además del ya citado Butiñá 2002a, 91-145-, Un nou "Libre de Fortuna e Prudència», «Revista de Lenguas y Literaturas Catalana, Gallega y Vasca», 8, 27-62; Una volta per les obres de Metge de la mà de Fortuna i de Prudència, en Miscel.lània Jordi Carbonell, V, Publicacions de l'Abadia de Montserrat 1993, 45-70, y Un nou nom per al vell del «Llibre de Fortuna e Prudència», «Boletín de la Real Academia de Buenas Letras de Barcelona», XLII (1989-90), 221-226. Cabe observar que la combinación de un clásico con Dante será característica en Lo somni, sellando pasajes de primer orden, como la loa de la mujer y el amor, en el IV libro; además, Metge manifiesta su familiaridad con los clásicos a través del recuerdo de un pasaje de la Divina Comedia: el conocido como «la sexta compañía», con la que se alude a los clásicos que Dante escogió para que le acompañaran a entrar en el castillo de la Fama. Puede verse Butinyà 2002a, 151. 
Su naturaleza precisamente provocó que el autor tuviera que acomodar su intelección en diversos grados, según las diferentes audiencias, de modo que, sin variar el plano literario - ni interrumpir la conversación ni alterar la escena onírica-, Metge se acomoda a los distintos tipos de comprensión; la razón es que tienen que entender la obra tanto los que quedarán convencidos de su conversión y serán favorables para con su delicada situación, como los sensibles a la nueva corriente, que se van a sentir identificados e incluso ilustrados, y los lectores del futuro, a los que dice también tener presentes.

En su aparición al autor, acompañan al rey Orfeo y Tiresias, personajes mitológicos que el monarca alega que entrañan un misterio; pero no van a ser ya meras figuras alegóricas, sino reales - -según Metge defiende en el caso de los demonios del pasaje del infierno, en el III libro, y según también mantenía repetidamente acerca de la Griselda de la ficción diciendo que era histórica-. Este concepto de autenticidad -en íntima relación con la teología poética de Boccaccio, a la que nos referiremos en breve - hace que, por medio de un rico juego culturalista, el autor esconda tras aquéllos unas claves de lectura; claves que son complejas, oscuras y disimuladas, pero a la vez no sólo inteligibles sino ordenadas y exactas, y que recoge del caudal de las dos grandes tradiciones, clasicista y cristiana, que va a conjugar en profundo sincretismo y armonía.

Estos primeros humanistas denigraban el uso de las figuras alegóricas con fines moralizantes en fáciles adjudicaciones de «buenos y malos» o con aplicaciones medicinales - muy a menudo en relación con mensajes espirituales-, al modo que se hacía a lo largo de la Edad Media, especialmente en glosas y traducciones. Ello suponía una reducción burda del significado del clasicismo y, por tanto, era uno de los hitos a derribar. El uso de la alegoría - a la luz del II tratado del Convivio y también del Somnium Scipionis- se proyecta ahora de un modo muy distinto sobre Lo somni, extendiéndose a toda la obra e impregnando todo el texto. Por ello, esta obra no se ha denominado alegoría onírica - como se ha hecho con el debate-, aun siéndolo.?

El realismo de la conversación impregna fuertemente a las dos figuras mitológicas —el mítico cantor del amor, Orfeo, y el amargado adivino, Tiresias--, puesto que ellas mismas han de ser ejemplares de lo que transmiten y el carácter verosímil era un requisito ${ }^{8}$ asimismo, sus palabras y su doctrina no son meros dichos a modo de eslóganes, al modo que -insistimos- se aplicaba anteriormente a las situaciones mitológicas.

Es curioso sin embargo que de estos viejos reclamos estereotipados tengamos una muestra cerrando Lo somni. En la imagen a la que nos referimos dicen lo mismo Agustín y Tiresias en las respectivas obras: «Ne forte cum Orpheo ab inferis rediens retroque rescipiens recuperatam Euridicem» (Secretum) y «No et

7 Es más, desde el punto de vista del género, el diálogo — aun siéndolo también- se podría acercar a la calificación de ensayo, en una línea de modernidad que corresponde a un terreno muy alejado de aquellas viejas alegorías. (Puede verse mi trabajo "Lo somni", en la línea del ensayo moderno, en prensa, citado en la bibliografía).

${ }^{8}$ Sobre este rasgo en los ejemplos, pueden consultarse las consideraciones de Ysem respecto al concepto de exemplum (Arnau de Lieja 2004, vol. 1, 8-18). 
girs detràs, axí com féu Orfeu» (Lo somni, ed. Casacuberta, 168, 12), aplicándolo ambos a un hecho moral de un modo típico al del estilo vetusto a extinguir. Este hecho tiene la siguiente explicación: la imagen está tomada del Secretum de Petrarca, dado que precisamente en el final de su obra Metge fulmina aquella filosofía petrarquesca mostrando cómo había caído en lo que este movimiento pretendía destruir. ${ }^{9}$

Aquellas figuras mitológicas no están retratadas en rigor en Lo somni, sino sólo definidas escuetamente de acuerdo con sus más estrictas caracterizaciones y desde el principio del diálogo: ${ }^{10}$ mientras que el significado que las sustenta y que ellas mismas encarnan se deriva de su misma conversación. Es un tipo muy distinto de alegorismo que el empleado anteriormente, al igual que comentamos con la figura de Amiclates, cuyo pobre uso en los sermones Metge remedaba.

La obra está compuesta por cuatro libros, cuya estructura se refuerza con pequeños engranajes literarios, ${ }^{11}$ de un modo parecido a como Riquer advirtió en su espléndida edición el enlace dialogado por medio de técnicas bebidas en la lírica trovadoresca (ed. Riquer, p. ${ }^{*} 160$ ). Pero si esto refuerza la continuidad, la solución a que recurrió el autor con una precisión y libertad magníficas para la variación dentro de la unidad consiste en que en cada uno de los libros se dé un fuerte contraste en la propia representación, contraste que se evidencia observando cómo él mismo va cambiando de posición respecto al personaje que lo representa e interlocutor principal; es decir, va dejando, como en una visión en secuencia, diferentes facetas de sí mismo.

Aunque estamos muy en los inicios de la época del retrato, ésta fue su salida para ser honesto y pragmático, sin perder autenticidad. Pues retratándose en cuatro poses distintas -que captarían o sintonizarían las distintas audiencias-, no se evadió de su mundo, como hacían en sus sueños los medievales, sino que en el suyo gracias a este recurso técnico pudo permanecer bien atado a la tierra, a la fidelidad textual, al realismo y al momento histórico. Retratos que además nos indican que estamos ante una obra de gran nivel y alta elaboración, que deja atrás ya la Edad Media.

En el I libro, reconocemos a un autor inteligente, representado con humor en uno de los personajes, Bernat, pero cuya intimidad de hecho se ha desdoblado en dos, pues su interlocutor, el que defiende las teorías positivas rebatiendo sus dudas, es también una parte de su yo, como anunció hace decenios el profesor Batllori y ha reconocido hoy ya toda la crítica ${ }^{12}$. La conversación de hecho es con él

9 Puede verse al respecto mi aportación al simposio de La Nucia y mi edición bilingüe de $L o$ somni.

10 «E acompanyaven-lo dos hòmens de gran estatura, la u dels quals era jove, fort bell e tenia una rota entre les mans; e l'altre era molt vell, ab longa barba e sens ulls, lo qual tenia un gran bastó en la mà", ed. cit., 18, 2-6

${ }^{11}$ Aunque en cuestión de fuentes hay mucho todavía que estudiar y analizar en esta obra - a pesar del incremento de su estudio a lo largo de la historia y especialmente en nuestros días-, he propuesto que unen el libro I y II las huellas de la misma fuente (el Corbaccio de Boccaccio), el II y el III (el Libre del gentil e los tres savis de Llull), y el III y el IV (el poema Lo desconhort, también luliano).

12 Véase Batllori 1995, 47, si bien recoge un trabajo de 1964; se observa ahí que Metge no replica a los argumentos de su oponente el rey Juan. 
mismo, o sea que en realidad efectúa un ejercicio de introspección, como deja ver desde el principio con el reflejo de las Confesiones de san Agustín; rasgo que, por otro lado, lo asemeja desde un principio al talante senequiano.

Finalmente, dado el consentimiento general de todas las tradiciones (con anteposición del papel de la gentilidad, mediando el De Ciuitate Dei $),{ }^{13}$ reconoce llegar a la iluminación y consuelo total; pero su escepticismo ha quedado esculpido en el texto con una enjundia sorprendente, denominando opinión a la fe. Hay que destacar que estos dos rasgos definen bien la figura de estos primeros humanistas, muy cercanos a los italianos, marcados por el ansia de pasar todo el pensamiento filosófico por el cedazo del racionalismo y también por fusionar los caudales culturales del clasicismo y del cristianismo.

La mirada del autor en este libro I es la propia de los retratos de la época, sagaz y connivente con el espectador - interactiva-, mirada que se aleja de la estática y plana de la pintura anterior.

En el libro II vemos otra cara: Metge hace broma y no se aguanta la risa, aunque aparentemente ofrece una imagen plenamente ortodoxa, que precisa con agudeza gracias a una firme formación teológica y respondiendo a la más rancia casuística acerca del más allá, en cuyos estadios va colocando —como hiciera Dante - a los muertos próximos de la casa real; asimismo, perfila de un modo magistralmente ambiguo los temas candentes del momento en torno al Cisma y a la Inmaculada Concepción. El autor habla aquí en una primera capa para quienes se convencerían de su conversión, la cual estaba confesando; si bien advierte hacia el final y en boca del rey Juan que hay varias audiencias, entre las cuales cita a la posteridad, comentario que por tanto augura más capas de lectura. En este libro presenta su cara más religiosa, sincera en cuanto al sentimiento - pues sería difícil dudar de expresiones tan emotivas y sentidas-, burlona en cuanto a las argumentaciones escolásticas - pues es fácil entrever la lectura divertida-.

Una distinción fundamental puede observarse ya en el uso de la alegoría, puesto que el ser expresión del mensaje divino lo utiliza el autor para sus propios intereses; es decir, se apropia del recurso de ocultar un misterio, de acuerdo con el uso más elevado de la literatura, el teológico, y según ya se había iniciado - sobre todo con Boccaccio- a través de la denominada teología poética. Con ello se elevaban los escritos profanos al rango de los sagrados y se dotaban de autenticidad y, por tanto, de ejemplaridad; de hecho, la literatura se abría a nuevas vías, desprejudiciadas, que dejaban lejos los tratados doctrinales a la antigua usanza, y se iluminaba ya por medio de nuevos componentes, entre los que cuenta mucho la estética. ${ }^{14}$

En el III el autor da un nuevo giro y adopta un talante de inocencia acribillando a Orfeo con preguntas acerca de las características materiales del infierno, hasta el punto que lo advierte su interlocutor:

${ }^{13}$ Si bien la disposición dialogística deriva previamente del Libre del gentil de Llull, que se abre a todas las doctrinas y tendencias sin estipular prioridades.

14 Atendí a este punto en concreto en Algunas consideraciones sobre poética medieval en el Humanismo catalán, «Revista de Poética Medieval» 12 (2004), 11-52. 
«E per què et fenys pus ignoscent que no és?» (ed. cit., 100,7).

Y es que Metge no había mostrado ser ningún incauto en la conversación anterior. Con este gesto ficticio de su personaje y por medio del tono abiertamente satírico que tiñe a todo este libro, va a propiciar que en el trasfondo de las fuentes se le pueda identificar con el inocente Ulises de la sátira II, 5, en que éste es corrompido por Tiresias a las puertas del infierno so cara de aconsejarle. Ya que aquí, Tiresias va a aleccionarle con frases del Secretum de Petrarca y va a recitar el Corbaccio para convencerle del engaño que sufre a causa de amar a las mujeres - tanto a la suya como a la amante que confiesa tener-, separándole en realidad del amor humano. La conversión, pues, profundamente, ofrece una lectura opuesta a la que se veía en la superficie del libro II; tanto el corruptor, el corrompido como el inocente cambian de alineación porque han cambiado los mismos ojos de Metge, con los cuales los retrata. Como anunciaba el rey a finales del libro II se esconde un misterio tras esos personajes mitológicos, pues a la pregunta acerca de su identidad, responde su amigo:

«-Tu —dix ell — te mets en carrer qui no ha eixida. Lleixa anar l'aigua per lo riu, que abans que ens partiscam, si subtilment hi volràs especular, coneixeràs gran part del misteri que hi està amagat; però no et faça cura de publicar aquell quan lo sabràs, car risc de gran perill te'n seguira e de poc profit a present», ed. cit., 83, 21-26.

Y en el IV, Bernat, desilusionado por el horror que ha escuchado de la boca del adivino, va a reaccionar - sinceramente, como en el I libro, pero ahora alta y francamente irritado-, mostrándose irónicamente explosivo y malicioso, y oponiendo desafiante otro concepto de virtud y de la mujer, hasta el punto de llegar casi a las manos con el adivino; puesto que él no se deja corromper por Tiresias (como ocurría con Francesco doblegado bajo los consejos de Agustín en el Secretum). Es tal su actitud de indignación que le lleva a devolverle el Corbac$c^{c} o^{15}$ en nueva redacción, aplicándolo a los hombres; su denuncia sin embargo no es sólo del misoginismo, sino intelectual y de amplia dimensión moral, como confirma el cierre de la obra. Si no fuera por la carga clasicista de todo Lo somni, que le imprime carácter, ante este pasaje se diría que estamos ante un furioso o apasionado escrito propio de etapas anteriores, sincero y explosivo, más cercano a un Guillem de Berguedà que a un humanista.

El Metge auténtico del libro filosófico inicial reacciona frente a Tiresias rechazando la doctrina petrarquesca que transportaba - bien marcada con motivo del tema de la Fortuna al inicio de este IV - , pues ésta no es coherente con la que se desprendía del libro I y que tanto le había satisfecho, como confiesa al final del mismo; filosofía que era resultado de la armonía entre los clásicos y el

15 Esta obra, además de ser exponente de aquella moral petrarquesca contraria al amor humano, coincide con la actitud que adoptó Boccaccio a la sombra de los consejos petrarquescos, patentes en las Seniles del libro XVII en las que se insertaba el Griseldis; con cuya traducción Metge anticipó ya su oposición al gran mentor de los humanistas (Butiñá 2002b), según hace explícito en el diálogo. 
cristianismo. Así, se retrata triste y desconsolado desde el principio de este cuarto libro, habiendo oído aquella moral contraria al amor humano, y «fort» triste y desconsolado al final del mismo libro, ${ }^{16}$ tras escuchar los consejos abreviados, también en boca de Tiresias y procedentes del Agustín del Secretum, pues afectaban además al trabajo y al ejercicio intelectual.

Pero hay que tener presente que Petrarca era quien enarbolaba el nuevo movimiento humanista; por lo que, en consecuencia, el disgusto hace que el autor se despierta del sueño sintiéndose como un muerto, ${ }^{17}$ Consciente de la vía de fracaso que había tomado el gran movimiento esperanzador y lo deplorable de sus efectos - como hacía patente en la carne de Boccaccio, al ser el Corbaccio el que vehiculaba la doctrina del Secretum-.

Donde se capta quizá mejor ese reproche moral —pues se identifica plenamente con su fuente- es a través de unas palabras de Séneca, de la epístola VIII a Lucilio, ${ }^{18}$ que son respuesta exacta al resumen final de los consejos egoístas de Tiresias (idénticos por tanto a los agustinianos en el último libro del Secretum). La identificación senequiana, aplicable a este pasaje final, ofrece un retrato muy puro del humanista catalán:

«Tu me, inquis, uitare turbam iubes, secedere et conscientia esse contentum? Ubi illa iubes, secedere et conscientia esse cibtentum? Ubi illa praecepta uestra, quae imperant in actu mori?"» (ed. Cardó, p. 15). ${ }^{19}$

Es decir, Metge lanza este último reproche a Petrarca a través de una pista que no es de localización difícil pues precisamente abre la obra bajo el reflejo de esa misma epístola, homologados ambos autores por la reclusión, el estudio nocturno y el sueño fulminante por cansancio de la intensa vigilia, rasgos que descifran la naturaleza del insomnio, de origen intelectual.

Pero en conjunto, el truco, la renovadora técnica estilística que ha utilizado, además del rico culturalismo por medio de las fuentes - que se abren en un amplio abanico, desde las que denigra a las que se identifica-, ha consistido en posar en cuatro posturas diferentes, en dejar cuatro autorretratos, a través de los

${ }^{16}$ Este pequeño dato puede servir de exponente de la proverbial exactitud del lenguaje metgiano.

17 Su actitud reprensora o correctora se confirma con otra clave situada en el cierre de la obra que es casi una pieza de precisión a modo de intertextualidad: la imagen del muerto inmóvil, la cual toma del prólogo al libro VIII del De casibus (Butiñá 2002a, 393-394) y que no ha podido reconocerse en otra fuente. Por medio de ella, Metge invierte los significados de la escena, pues allí Boccaccio era convertido por Petrarca. El recurso literario de recortar-pegar textos reconocidos o de la Antigüedad, que se empezaba a emplear y que denominamos imitatio, es una técnica literaria que Metge utiliza no sólo con buen gusto sino con extrema pericia; de modo similar escultores y pintores representaban los modelos clásicos.

${ }^{18}$ He señalado esta fuente en distintos puntos de la edición bilingüe. (Puede verse mi trabajo en prensa para el volumen de la Universidad de Valladolid).

19 Según la traducción catalana: «¿Tu, dius, em manes que m'aparti de la turba i m'acontenti amb la meva consciència? ¿On són aquells preceptes vostres que prescriuen de morir damunt la tasca?», ib. 
cuales hoy reconocemos su gran habilidad. Ellos son buen testimonio de lo que fueron estos primeros humanistas, que supieron usar así de la belleza en el tratamiento de los textos, aplicando muy altas dosis de racionalidad para fines pragmáticos ante los acontecimientos adversos. La convulsión del tiempo era total en su modo de afectar a los hechos humanos, ${ }^{20}$ desde el sentido de la literatura al concepto de la moral o a la reacción frente a la fortuna. Y Metge no admitía un amago, aunque proviniera del mismo mentor del movimiento; además, de dejarle hundido la desviación ideológica que había tenido la oportunidad de constatar en la obra boccacciana y que arrastraba desde el Griselda.

Que Metge era experto en retratar y caricaturizar lo avala todo el diálogo; así puede verse en los breves rasgos con que configura la preciosa galería de modelos que toma de Valerio Máximo, en quien se inspira para su exposición virtuosa femenina. Y aún más en el retrato de las cuatro reinas vivientes, que - al margen de los toques clasicistas- posan con un realismo que — con la licencia del comparatismo- quizá en el arte pictórico no se alcance hasta Goya.

Observémoslas algo más de cerca: ${ }^{21}$ la primera, Elisenda de Montcada, era una figura de indiscutible ejemplaridad. Se trata de la tercera mujer de Jaime II de Aragón que, al enviudar, se retiró junto al monasterio que estaba construyendo en Pedralbes, en las afueras de Barcelona; el sello que le otorgó este hecho es tal que aparece en los documentos, según la denomina Metge, como «regina de Pedralbes» (ed. Riquer, 338-339 y nota 24). Cabe señalar también que en el claustro del monasterio figuran el escudo real y el de la casa de Montcada, ya que Elisenda era hija del Gran Senescal de Cataluña, don Pedro II de Montcada; reparamos asimismo en que en una capilla del mismo se ubica el principal conjunto pictórico de ese siglo — concluido en 1346-, que alberga la obra de Ferrer Bassa, autor que introduce el estilo italogótico, con influencia sienesa y florentina, de fuerte realismo en la fisonomía y expresión. ${ }^{22} \mathrm{Y}$ hay que tener en cuenta además que estos caracteres son acordes con la tendencia progresiva de la época hacia el auge del yo.

Del retrato de la reina Leonor ${ }^{23}$ - a quien Metge recordaba con agradecimiento al ser la primera a quien sirvió en la Cancillería, según hace decir al rey Juan-, se resaltan detalles que debió tener ocasión de vivir muy de cerca. Así, la referencia a sus cualidades en la suplencia de su marido, durante la guerra de

20 Según Batllori $(1995,22)$, fue un movimiento «renovador de tot l'home».

21 Desde una visión particularizada interesa remitir al trabajo de Núria Silleras, donde se enfoca su estudio desde el nuevo concepto de «reginalitat»: «és una reflexió d'una realitat històrica que comparteixen les societats medievals de la Península Ibèrica -i no es pot concebre una visió històrica total sense tenir en compte aquesta realitat. Els treballs de reginalitat també poden servir per introduir a les reines, $\mathrm{i}$ amb elles a les dones, dins del cànon del que es concebeix normalment per a la 'història' a estudiar, no només han de ser objectes de monografies especialitzades» (2006: 142).

${ }_{22}$ Si este gusto por el retrato se anticipa en Italia, hay que destacar que alcanza campos como el de los códices y en puntos que nos afectan, pues allí se ha reconocido a Boccaccio y Petrarca dibujados con sus retratos en relación con la discusión literaria a raíz del Griselda (Albanese 2000).

${ }^{23}$ Era madre de los dos reyes de la Corona de Aragón próximos a Lo somni, uno presente en la ficción y el otro, lector y destinatario, respectivamente Juan I y Martín I. 
Castilla. Un estudio del profesor José Luis Martín, a raíz de este hecho, ${ }^{24}$ cierra con una anécdota que no sólo no desmerecería de la admiración de Metge sino que incluso parece estar detrás de su alabanza; se trata de los esfuerzos que realizó a efectos de conseguir apoyos para su marido, llegando a amenazar con hacer huelga de hambre:

«Notori és a tothom que, si no fos per sa indústria e esforç, tot lo regne fóra perdut; car lo senyor Rei, son marit, ocupat lladoncs en la frontera per resistir a sos enemics, no podia entendre en les altres coses necessàries a la guerra, les quals ella sobre força humanal suplí» (ed. cit., 143, 25-144, 2).

Se explica en el trabajo citado cómo era preciso para la empresa la aprobación de la ayuda económica por parte de las Cortes -fueron en Barcelona, en 1365-, así como los problemas que existían para su aprobación: «Cincuenta días después de haberse iniciado las reuniones... da la reina un plazo de 24 horas para que se pongan de acuerdo... El plazo fue ampliado otras 24 horas... El acuerdo final se haría público el 14 de diciembre, tres meses más tarde, a pesar de que el 23 de septiembre la reina amenazase a las Cortes con iniciar una huelga de hambre si aquel mismo día, antes de comer, no se llegaba a un acuerdo y se hacía pública la oferta conjunta: ' $E$ aço volem e requerim que façats ara de present ans de dinar car nos james no us entenem a dinar entro que la presentacio del dit do nos haiats feta per tal com veem que huy mes la triga de un dia es mort e destruccio del Senyor Rey e del Regne», Martín 1989, 111.

Cabe destacar también que tanto este detalle como el de la pacificación de Sicilia (que fragua en tiempos de Martín el Joven - nieto suyo- pero del que Metge destaca la labor previa de la reina), de hecho aminoran el valor de los varones; al igual que sucede en múltiples ocasiones a lo largo del diálogo. $\mathrm{O}$ sea que esta alabanza femenina, incluye en realidad una crítica solapada a los hombres que le eran próximos; la revancha de Metge hacia el misoginismo de Tiresias, por tanto, no se da sólo en la segunda parte del libro IV en alegato abierto. ${ }^{25}$

Y es digno de destacar este hecho - la merma de loa al rey reinante - por haberse considerado normalmente Lo somni como una obra de autojustificación; sin embargo, obsérvese que Metge no sólo le resta mérito en sus actividades políticas, sino que además no cita al rey Martín - al principio de ese párrafo-

24 J. L. Martín Rodríguez, Las Cortes de Pedro el Ceremonioso, «Anuario de Estudios Medievales», 24 (1989), 108: «Retenido el monarca en la frontera valenciana, presidió las Cortes la reina Leonor en cuanto Lugarteniente General, y sus gestiones o las de sus consejeros hicieron llegar al ánimo de los procuradores la idea de que la recuperación de los lugares ocupados por el castellano era defensa necesaria».

${ }^{25}$ Puede verse con claridad también en un análisis cuidadoso del listado de mujeres deplorables por su comportamiento para con los hombres, listado que da en las últimas recomendaciones $\mathrm{Ti}$ resias; o bien a través de un rastreo del lenguaje del pasaje en que reproduce el Corbaccio, que es favorable a la mujer en los más ínfimos detalles, diferenciando incluso el tono cuando las palabras femeninas están pronunciadas por el adivino. Ambos aspectos pueden seguirse en los puntos correspondientes en la edición que he preparado para Atenea. 
como hijo de la reina tan admirada, cuando podía haber sido una ocasión muy propicia para incluirle en el efecto del brillo.

La defensa de la mujer ${ }^{26}$ y los retratos de las mujeres por parte de Metge eran radicales contra la misoginia y acentuadamente femeninos. El renombre de Leonor de Chipre - el siguiente retrato-- cuya mala fama (ed. Riquer, p. 340 y n. 28) como asesina de su marido llega a reflejarse en los Cuentos de Canterbury de Chaucer, puede quedar atemperada por la protección que le otorgaron los reyes en Barcelona, desde 1381; pero sin duda hay que apreciar que Metge alabe su coraje prescindiendo del hecho luctuoso, cuya autoría resalta que recae en sus hermanos y vasallos ${ }^{27}$. Nueva protección, pues, hacia la mujer.

En la alabanza de Sibila de Fortiá, reina vituperada repetidamente en su tiempo, ${ }^{28}$ cabe destacar la comparación con Escipión, a todas luces misteriosa para la crítica, y especialmente álgida para Metge al afectar a la figura del Africano, héroe tan encumbrado en el mismo diálogo. Pero no hay que dejar de reparar en que no se concreta de qué Escipión se trata, mientras que todas las otras referencias - precisamente hacia distintos Escipiones - han venido cuidadosamente especificadas; por lo que de nuevo el ingenio de Metge salvaba la situación siendo favorable a la mujer en general y burlando al lector incauto o superficial. La defensa que estaba llevando calurosamente a cabo frente a Tiresias era verdaderamente genérica.

Al tratar de la reina Violante, la esposa del amigo fallecido, hay que resaltar que la última nota, el amor conyugal, había sido ya comentada —desde la óptica del afecto del marido- en el libro II, donde con un fragmento del De Trinitate (Butiñá 2002a, 287) que se refería a las virtudes de la vida futura garantizaba el amor del difunto esposo. Aquí añade con bellísima expresión la virtud de la liberalidad, ${ }^{29}$ parafraseando expresiones de Valerio Máximo:

${ }^{26}$ Expuse las líneas principales en Bernat Metge, defensor de la dona i l'ideal de la pau, «Revista de Filología Románica» XX (2003), 25-40, si bien se puede ver un enfoque más particular en las actas de La Nucia y sobre todo a lo largo de mi edición bilinguie. Cabe entender la selección de figuras femeninas actuales comprometidas, de difícil explicación, como un desafío o reto en su misma defensa de la mujer, al asumir casos extremos; al igual que no defiende sólo el amor a la mujer en general o hacia su esposa sino el caso de una horrible y repugnante amante, o bien cabe advertir también que la protagonista de su otra traducción es La velletona.

27 «Qui et poria explicar la gran animositat que la regina Dona Elienor de Xipre hagué en lo gran perill al qual per sa honor deliberadament exposà la sua persona en la venjança que féu de la mort del rei En Pere, marit seu, per sos frares e vassalls perdicionalment perpetrada?», ed. cit., 144, $10-16$.

${ }_{28}$ Entre otras acusaciones, se halla la de evadir bienes reales a la muerte de su marido, por lo que fue sitiada por el entonces infante Martín, castigando a sus secuaces; posteriormente, su fama fue rehabilitada, asistiendo junto a la nueva soberana al entierro de Juan I. (Véase la ed. Riquer, $340-342$ y nota 29 ).

${ }^{29}$ Los ejemplos de liberalidad corresponden a los que da Valerio Máximo: IV, cap. 8, Sobre la generosidad: 2, sobre Busa, mujer rica que dio alimentos a la ciudad de Canusio; y entre los ejemplos extranjeros, 8,2 , se halla el de Gilias de Agrigento, de quien se dice que estaba más preocupado por dar dinero que por obtenerlo y cuyas pertenencias eran patrimonio de la comunidad. Del cónsul Quinto Fabio Máximo, que abunda en notas en la obra latina, podrían concretarse las 
«La sua casa és estada, e és encara, temple de lliberalitat e molt pus ocupada en donar que en resebre» ed. cit., 145, 6-8,

$\mathrm{y}$, seguidamente, recuerda su vínculo como servidor. ${ }^{30}$

Podíamos desprender de todo ello una interesada intencionalidad de alabar a la monarquía y casal de Aragón, pero como por encima de todo en Lo somni hay que atender a la fidelidad al amigo muerto - $\tan$ bellamente resaltada con el De amicitia-, cabe desprender también que la alabanza de las otras dos reinas vivas de dudosa moralidad se pueda hallar en relación directa con la bella loa de la reina Violante, quien no olvidemos que - por mandato del difunto a finales del libro II- debería estar entre quienes leyesen esta obra. En cierto modo como harán los pintores de corte introduciendo, junto a los personajes reales a encumbrar, enanos o meninas.

Su modelo de virtud anclado en la clasicista determina las pinceladas sueltas procedentes de personajes de la antigüedad; así lo hemos comentado en algunas de las reinas actuales, pero siempre su mano va guiada por el afecto y la fidelidad. ${ }^{31}$

Y en aspectos formales estos retratos nos deparan una ocasión más para apreciar el naturalismo que avanzaba arrollando en esta época. Cabe poner de lado cualquiera de estos retratos -o bien el del rey Juan, modelo de naturalidad, tan exacto como conciso ${ }^{32}$ - con los que se estilaban entonces; no ya antes - pues hemos comentado el rompimiento que se ha dado-, sino también algo más tarde, bajo las nuevas líneas de actuación literaria, de acuerdo con la moda en diálogos y retratos de ascendencia clasicista; ${ }^{33}$ frente a ellos, este autor sobresale por su equilibrada naturalidad.

que aluden a sus acciones benéficas para con la ciudad (II, 2-9). Cabe señalar que no se habían localizado correctamente todas estas referencias en ediciones anteriores, según puntualizo en mi edición.

30 Sigue: «e jo deig-ho saber entre los altres, qui de mon flac poder l'he servida llongament». Hay que resaltar que era especialmente necesario asegurar esta virtud en un momento en que se acusaba de dilapidación al reinado anterior, pues Metge podía ser un buen aval como testimonio privilegiado por su cercanía y servicios, como arguye en este mismo pasaje; especialmente era preciso hacerlo cuando la misma reina, de origen francés y criticada por algunos moralistas - como Eiximenis, de mentalidad medievalizante-, había contribuido a la adquisición de libros y otros refinamientos cortesanos.

${ }^{31}$ En resumen, consideramos que era algo muy serio para Metge el tema del vituperio y la alabanza de la mujer en contenidos; por ello, no podemos comprender este comentario: «Metge es pren amb una certa frivolitat tot aquest afer del vituperi i de la lloança de la dona», Lo somni, ed. L. Badia, «Mínima minor» 86, Quaderns Crema, Barcelona 1999, 30.

32 «un hom de mitja statura, ab reverent cara, vestit de vellut pelós carmesí, sembrat de corones dobles d'aur, ab un barret vermell en lo cap», ed. cit., p. 17-18. Sin embargo, quizá uno de los aspectos más torpes o inmaduros sean las introducciones a las intervenciones con las que marca los gestos de los hablantes, entorno en el que aún falta técnica narrativa, que hasta medio siglo después no aparecerá en estas letras, gracias al autor del Curial, quien tanta narrativa francesa había leído; mientras que domina con maestría los trazos de las preguntas y respuestas, que es lo propio del diálogo, el género que probablemente más habría leído Metge.

${ }_{33}$ Véanse, por ejemplo, los diálogos de Diego Ramírez de Villaescusa (1498) a la muerte del príncipe Juan, heredero de los Reyes Católicos, donde la Muerte habla con la reina Isabel, repre- 
Y en el campo del retrato, ¿dónde sitúa la virtud cristiana, religión y doctrina en la que él se considera inserto (ed. cit., 141, 12)? Sólo en la desgraciada Griselda, en cuya realidad es lógico que insista —llamándola historia-si debía ser ejemplar (ed. cit., 142, 23), además de responder a la teoría literaria de su autor, Boccaccio. Su figura se enmarca en un precioso cuadro, probablemente de ascendencia boccacciana, que ya ha sido valorado por la crítica. ${ }^{34}$

Todavía sobre Violante, advirtamos una exquisita precisión, al separarla respecto a la cualidad de la que se burlará a continuación en la reina María:

«Si oiràs parlar d'ací avant d'amor conjugal e d'aquesta no et serà feta singular menció, no hages per bon historial ni disert aquell qui en parlarà, car sàpies que poques en nombre són a ella estades eguals», ed. cit., p. 145, 13-17.

Con lo cual ha diferenciado ambos casos y a los lectores nos ha confirmado la lectura irónica de la siguiente figura, la entonces reinante María de Luna, de acuerdo con la posibilidad de lectura crítica hacia el poder establecido que ya hemos apuntado. Último retrato, el de la mujer del rey Martín, que merece una atención especial.

Ya desde el principio, en que hace una alusión a la brevedad y a la colocación de su loa como cierre, nos hallamos ante una alabanza de doble filo: es decir puede leerse también que se está creando la excusa para hablar poco de ella y colocarla al final. ${ }^{35}$ Se subraya la posibilidad crítica al empezar a relevar su amor conyugal, cuando pocas líneas antes, a propósito de la reina Violante, había dicho que si no se le tenía en cuenta a ella en dicho asunto, se trataba de un falso historiador; luego, la siguiente figura ya quedaba implícitamente en un segundo lugar. Es decir, María de Luna no ocupaba el primero; dato negativo que hay que yuxtaponer al que ya hemos advertido, acerca de que el tono de la loa sea tan exagerado que suena a falseado.

Ello se comprueba con la extensión relativa a la anécdota de la fidelidad a su esposo, comparándola con Penélope a raíz de hallarse él en la guerra en Sicilia, puesto que los sicilianos se rindieron a los dos meses y la ausencia del rey alcanzó poco más de 4 años (de principios de marzo de 1392 a 27 de mayo de 1396); mientras que en el caso que se compara de la antigüedad, el de Penélope,

sentada como una persona horriblemente fea, en González Rolán 2006, cii. (Este interesante estudio de recopilación desde varios ángulos es una cantera para el comparatismo sobre todo por el cambio que ha ido acusando la sociedad).

34 «impagable su presentación como cuento recitado al amor de la lumbre, para aliviar la pesadumbre del hilado», Conde, J. C., e Infantes, V., La Historia de Griseldis (c. 1544), "agua y peña» 12 , ed. M. Baroni, Viareggio-Lucca 2000, 41. (Sobre la procedencia boccacciana de la imagen puede verse Butiñá 2002b, 44-48).

35 Con el hecho de las prioridades ha jugado Metge desde el principio, dejándolo abierto a diversas interpretaciones o bien escudándose en ocasiones - como la que tiene lugar en relación con las autoridades de los gentiles- que podían serle reprochadas. Compárese la excusa que estamos viendo, por ejemplo, con la cortesía por empezar a hablar, a principios del III libro; allí, Orfeo prevenía que se le tildara de arrogancia, pero no se cuestionaba ni cabía duda alguna acerca del valor de su interlocutor. 
cierra ésta el primer capítulo de las Heroidas diciendo que Ulises se fue siendo ella joven y que, por pronto que vuelva, parecerá vieja.

Las otras cualidades parecen, sin embargo, sinceras por parte de Metge: la habilidad política de la reina en los asuntos internos y su flexibilidad e indulgencia para con los encartados en el proceso. Gestos que subraya de nuevo con nobles trazos: clasicista en el primer punto y nada menos que con los salmos en el segundo, fuente religiosa que cuadra bien además para la mujer de Martín el Eclesiástico. Por ello, no es una mera imagen retórica el argüir que en el retrato de estas reinas se incluye retratado el mismo autor, a ojos de quien lo advierta y a causa del fuerte y complejo subjetivismo; en cierto modo también es algo que -al ritmo del desarrollo de técnicas y tendencias paralelas en las artes-consagrará Velázquez en las Meninas.

En esta bella exposición selectiva de retratos, Metge deja ver su risa contenida, su muy seria burla, su malicioso alabar alabando menos, así como los brochazos seguros de nobleza como corresponde a la categoría de la realeza. Esta apertura a distintas visiones - según le convenía ejercer a fin de convencer a cada audiencia de una faceta de su personalidad, amoldable a la misma verdad subjetiva que está demostrando, según alega a principios del libro IV-,${ }^{36}$ es coherente con el dominio y fluctuación de la imagen que vimos ya que da de él mismo, cambiante en cada libro.

Con este alto uso el sueño volvía a la dimensión de los clásicos, como lo empleaba Cicerón, bajo cuya conversación emplaza Metge su diálogo y a cuya sombra ha homologado actitudes suyas, como la mencionada de la amistad. ${ }^{37} \mathrm{Y}$ con la referencia a las fuentes clásicas vamos a cerrar esta exposición, es decir con la vuelta del sueño, del medioevo, a la Antigüedad. Observemos la mención que se hace del pasaje del Somnium Scipionis, emulándolo y dándole nueva vida al asimilarlo en una nueva ocasión regeneradora. Metge retoma y adapta a su obra aquel papel fundamental onírico: el autor, con la exactitud que le corresponde como notario, se sitúa en el De Republica, sin dejar de mencionar la deuda a los modernos, a propósito del Africa. ${ }^{38}$

Aquella ocasión tan noble hace de espejo a la suya, atando pasado y pre-

36 «-No m'estaria bé — dix ell- mentir deliberadament.

- Pijor staria a mi —diguí yo- no deffendre veritat, majorment que hi puixa entrevenir culpa mia.

-Pus així és -dix ell-, navec cascú ab son vent.

-A fer covendrà — responguí yo-, car a diverses térmens anam», ed. cit., p. 133, 11-19.

De aquí que haya todavía hoy interpretaciones en las antípodas unas de otras, hecho que es positivo para la ciencia y que tiene aquí su explicación, en la falta de verdad objetiva, como bien alega Metge con su misma obra. Si bien desde las posiciones de la crítica actual es lamentable la falta de transparencia y comunicación - requisito de toda pretensión de actividad científica-, a raíz precisamente de aquella variada visión de Lo somni.

${ }^{37}$ La huella ciceroniana es una de las más profundas; se han reconocido como principales $\mathrm{De}$ amicitia, De Republica, De senectute y las Tusculanae (Riquer 1959).

${ }^{38}$ Cabe destacar el valor precoz de su cita cuando el poema - salvo el pasaje de la muerte de Magón- tardó en difundirse, pues no se editó hasta 1396. 
sente por el préstamo que el rey Juan le había hecho del libro en la versión de Macrobio, que era la entonces conocida. Dice el rey rememorando a Cicerón:

«E dix aquelles coses que son pare, Publi Escipió, li havia dit sobra la dita immortalitat, quan aprés sa mort li era aparegut en lo somni que feu, lo qual recita Tul-li, en lo libre De Republica, e Petrarca semblantment en l'Africa; l'exposició del qual, si et recorda, feta per Macrobi, te prestí en Mallorca, e la't fiu diligentment estudiar, per tal que jo e tu ne poguéssem a vegades conferir» (ed. cit., 42, 12-21).

Es decir, no sólo la línea temática o el título de la obra son los mismos sino que también es idéntica la situación: Publio Escipión estuvo hablando de la inmortalidad antes de morir y es rememorado en una obra sobre el sueño; lo mismo está ocurriendo con la conversación que mantuvo él con el rey en vida y que ahora recuerdan en Lo somni. La conciencia de dignidad al colocar su obra en esta tradición es obvia; así como también la de incluir el Africa en la dinámica ennoblecedora.

Ahora bien, llama la atención la inclusión de la obra de Petrarca de manera tan manifiesta; y además, ¿cómo aparece aquí la silueta del contemporáneo italiano, tan reprendido en los últimos libros? A principios del libro II se entiende bien que le sirve de escudo en referencia al tema del juicio por apoyar el prestigioso italiano en aquella cita del De remediis - claramente iluminada por Metge, con cita expresa y con focos-, la causa de la muerte súbita que beneficiaba a los encausados. Pero esta otra cita del poema es aleatoria e injustificada, por lo que merece ser analizada y vamos a proponer una explicación que encaja con la interpretación global de Lo somni.

En primer lugar cabe entender aquella cita del Africa, en punto tan crucial, como la respuesta a la insistencia de Agustín al final del Secretum a fin de que Francesco abandonara su redacción y ese tipo de escritos, aconsejándole, como en los viejos tiempos, pensar sólo en la muerte y en su propia conciencia; puesto que este pasaje va a ser crucial también en el cierre de Lo somni. El tipo de ocupaciones que se obviaban - y que hoy podríamos denominar de resonancia social- están en consonancia con el cambio del concepto del trabajo. Y estos consejos tienen su reflejo puntual en las últimas palabras de Tiresias; $;{ }^{39} \mathrm{es}$ decir, Metge los recogía produciéndole el desconsuelo final -que hemos visto anteriormente-, pues eran expresión del rechazo de una vida recluida dirigida al provecho comunitario, así como de las obras con preminente carga estética.

Por lo que Metge respondería al rechazo manifestado hacia el Africa con su adhesión más entusiasta - no al final del libro en este caso, sino en el Iplantándola en lugar encumbrado, o sea colocando el poema petrarquesco en el lugar más alto de su obra.

De este último comentario cabe resaltar también su concepto de la literatura; pues se evidencia que para Metge la más noble es la línea en la que em-

${ }^{39}$ En conjunción con el punto comentado en la nota 9 supra, puede verse mi aportación al simposio de La Nucia. 
plaza su obra y esta obra petrarquesca. Concepto además que otorgaba ya nuevos encuadres respecto a la Edad Media al modernizarla con la vuelta a los antiguos; con lo cual nos encontramos ya a la vuelta de la esquina del Renacimiento.

No tenemos el retrato de Petrarca realizado por Metge, pero sus distintas opiniones y gestos, admirativos y de reprensión, acerca de algunos hechos que afectan al nuevo movimiento han quedado bien plasmados en Lo somni.

Del retrato más estricto hemos ido pasando a encuadres más amplios e incluso a escenas o a cuadros que asume o rememora el autor, pero también cabría atender a la caracterología o a las situaciones comunes; así, es valiosa a mi entender la coincidencia respecto a la primera connotación que da de sí mismo, en el arranque de la obra - estudiando y recluido, de noche, oprimido por el agobio de las preocupaciones públicas-, conforme al dibujo que la mayoría de aquellos primerísimos humanistas habían perfilado de ellos mismos en las cancillerías italianas. ${ }^{40}$ Pero ello implica una extensión del concepto de retrato y en esta aproximación hemos preferido centrarnos en algunos aspectos que hemos considerado primarios o fundamentales. Baste, pues, aquí reseñar que técnica y arte, al unísono, estaban empezando a cambiar, en la línea de la mayor veracidad y la mejor naturalidad.

Así pues, el diálogo Lo somni, el sueño con que Metge emula el Somnium Scipionis y que enlaza con aquella misma esperanza - la vida futura alcanzada por la moral-, no sólo a causa de las técnicas innovadoras y la lengua renovada ${ }^{41}$ es muy distinto ya del sueño medieval, pues abre una nueva época, ${ }^{42}$ La alegoría ha cambiado profundamente, recuperando un uso que tuvo en el clasicismo, al igual que hemos visto que lo hace la caracterización de sus personajes.

Y aunque los sueños del Renacimiento hispánico que el Humanismo ha hecho renacer alcancen su altura, no lograrán la belleza y racionalidad de Lo som$n i .^{43}$ Sin embargo, las técnicas artísticas, como la relativa al retrato, seguirán una ascensión manifiesta en las diversas artes, y en literatura harán desarrollar y per-

4) Desarrollo este punto en mi trabajo para el volumen de la Universidad de Valladolid sobre la traducción.

${ }^{41}$ La renovación en su caso no es meramente formal, como observó Hvizinga que ocurría en las cortes de Borgoña.

${ }^{42}$ Su modo de remitirse al clasicismo es precisamente oponiéndose —detallada y concisamente, pero en profundidad - al modo empleado en la Edad Media, en la que aquel había hasta entonces pervivido (Curtius).

${ }^{43}$ Por todo lo expuesto diferimos de la concepción de esta obra como «un producte merament literari amb el qual l'autor podia autojustificar-se d'una manera elegant» (Mahiques 2005, 23), y especialmente como un tratado devoto (idea con la que se cierra el artículo de Mahiques, ib., 28). Contrariamente, lo calificamos como una alta obra literaria, de contenido filosófico-moral, interesante como testimonio para la historia de la cultura por su ataque a la mentalidad escolástica y medieval; aunque la audiencia de rango tradicional sí que lo leería como tratado moralizante, gracias a la habilidad del autor en el arte de retratarse. Pues toda la finalidad de Metge, en ésta y en las demás obras, era derrumbar el viejo edificio, el mismo objetivo que pretendían los humanistas. 
feccionar aspectos que hemos comentado aún imprecisos en Metge. ${ }^{44}$ Pero su precedencia en este ejercicio del retrato y el tan peculiar del autorretrato también es digna de tenerse en cuenta.

\section{BIBLIOGRAFÍA}

Albanese, G., Un dittico umanistico: Petrarca e Boccaccio, en Immaginare l'autre. Il ritratto del letterato nella cultura umanistica, a cargo de G. Lazzi y P. Vitti, Polistampe, Florencia 2000, 149-169.

ARNAU DE LIEJA, Recull d' exemples i miracles ordenat per alfabet, ed. de J.-A. Ysern, Barcino, «Els Nostres Clàssics», Barcelona, 2004

Batllori, M., Obra completa, V, De l'Humanisme i del Renaixement, pról. de E. Duran, ed. Tres i Quatre, València 1995.

Butiñá, J., Metge, buen traductor de Séneca, en Sobre la traducción, coord. por R. Recio, Universidad de Valladolid, en prensa.

-, Humanisme i Traducció. L'Humanisme traduït, II Curs Internacional de Clàssics Valencians (Clàssics valencians poliglotes), La Nucia 2006 (actas en prensa).

- El sueño en la literatura catalana medieval a través de los textos humanistas, Colloque International «Le rêve médiéval et ses métamorphoses», Bucarest 2006 (actas en prensa).

—, «Lo somni», en la línea del ensayo moderno, en «Transversal» V, coord. por Assumpta Camps, Universidad de Barcelona, en prensa.

-, La recepción del Humanismo (del siglo XIV al XV); Bernat Metge: el diálogo de «Lo somni», en www.liceus.com (2004).

-, En los orígenes del Humanismo: Bernat Metge, Madrid, UNED 2002a. (Puede consultarse en www.uned.es/453196).

—, Del «Griselda» català al castellà, «Series Minor» 7, Real Academia de Buenas Letras de Barcelona, 2002b. (Puede consultarse en www.uned.es/453196).

CuRTIUS, E. R., Literatura europea y Edad Media Latina, 2 vols., Fondo de Cultura Económica, Madrid $1989^{5}$.

González Rolán, T.; Baños Baños, J. M.; Saquero Suárez Somonte, P., El humanismo cristiano en la Corte de los Reyes Católicos. Las consolatorias latinas a la muerte del Príncipe Juan, ed. Clásicas, Madrid 2006.

Hvizinga, J., El otoño de la Edad Media, Revista de Occidente, Madrid $1961^{5}$.

${ }^{44}$ El género del diálogo se aportó renovado pero no tuvo continuidad con rigor filosófico pues cayó en el didactismo. El estilo de Lo somni, en prosa agradable pero exigente, de ficción pero desgajado de la historia, de las aventuras y de la trama sentimental, anuncia más bien el género del ensayo (sobre este punto puede verse el trabajo citado en la bibliografía, en prensa). Mientras que el retrato — punto de este diálogo- eclosionaría, por otras vías y muy lógicamente, en la novela. 
KRAYE, J., Introducción al humanismo renacentista, trad. a cargo de C. Clavería, Cambridge University Press, Madrid 1998.

LE Goff, J.; SchmitT, J.C., dirs., Dictionnaire raisonné de l'Occident médiéval, París 1999.

Mahiques Climent, J., «Lo somni» de Bernat Metge i els tractats d' apareguts, «Llengua i Literatura» 16 (2005), 7-31.

Metge, Bernat, Lo somni, ed. por J. M. a de Casacuberta, «Els Nostres Clàssics», Barcino, Barcelona 1980.

—, Lo somni, trad. e intr. de J. Butiñá en www.ivitra.ua.es (2004).

-, Lo somni. El sueño, ed. bilingüe, intr. y notas de J. Butiñá, Centro de Linguística Aplicada Atenea, Madrid, en prensa.

Riquer, M. DE, Història de la Literatura Catalana, I-II, Ariel, Barcelona 1964.

_, Obras de Bernat Metge, ed. y estudio, Universidad de Barcelona 1959.

Rubió I Balaguer, J., Obres de Jordi Rubió i Balaguer, VIII, Humanisme i Renaixement, Publicaciones de la Abadía de Montserrat 1990.

SÉNECA, Lletres a Lucili, I-IV, a cargo de C. Cardó, «Fundació Bernat Metge», Barcelona 1928-1931.

SIlleRAS FeRnÁNDEZ, N., Reginalitat a l'Edat Mijana hispànica: concepte historiogràfic per a una realitat històrica, «Boletín de la Real Academia de Buenas Letras» 50 (2006), pp. 121-142. 